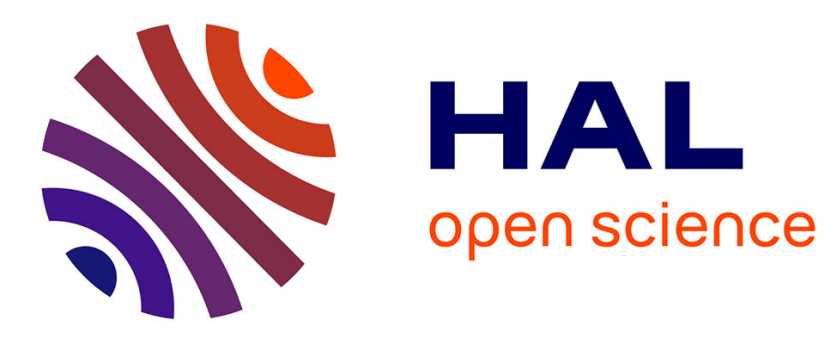

\title{
Rapid Manufactured Textiles
}

Guy Bingham, Richard Hague, Christopher John Tuck, Andrew Long, Jonathan Josiah Crookston, Martin Sherburn

\section{To cite this version:}

Guy Bingham, Richard Hague, Christopher John Tuck, Andrew Long, Jonathan Josiah Crookston, et al.. Rapid Manufactured Textiles. International Journal of Computer Integrated Manufacturing, 2006, 20 (01), pp.96-105. 10.1080/09511920600690434 . hal-00513379

\section{HAL Id: hal-00513379 \\ https://hal.science/hal-00513379}

Submitted on 1 Sep 2010

HAL is a multi-disciplinary open access archive for the deposit and dissemination of scientific research documents, whether they are published or not. The documents may come from teaching and research institutions in France or abroad, or from public or private research centers.
L'archive ouverte pluridisciplinaire HAL, est destinée au dépôt et à la diffusion de documents scientifiques de niveau recherche, publiés ou non, émanant des établissements d'enseignement et de recherche français ou étrangers, des laboratoires publics ou privés. 


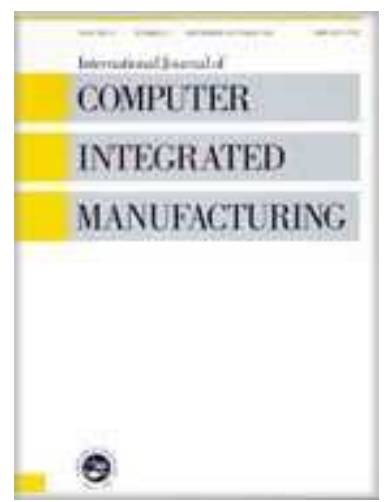

\section{Rapid Manufactured Textiles}

\begin{tabular}{|r|l|}
\hline Journal: & International Journal of Computer Integrated Manufacturing \\
\hline Manuscript ID: & TCIM-2006-IJCIM-0030.R1 \\
\hline Manuscript Type: & Original Manuscript \\
\hline Author: & $10-$ Submitted by the \\
& $\begin{array}{r}\text { Complete List of Authors: } \\
\text { Materials and Manufacturing engineering } \\
\text { Crookston, Jonathan; Nottingham University, school of Mechanical, } \\
\text { Mague, Richard; Loughborough University, Wolfson school } \\
\text { Materials and Manufacturing engineering } \\
\text { sherburn, Martin; Nottingham University, school of Mechanical, } \\
\text { Materials and Manufacturing engineering }\end{array}$ \\
\hline Keywords: & RAPID MANUFACTURING, CAD, DESIGN \\
\hline Keywords (user): & TEXTILES, SMART TEXTILES \\
\hline &
\end{tabular}

\section{S ScholarONE \\ Manuscript Central}


International Journal of Computer Integrated Manufacturing, Vol. X, No. X, Month 2004, xxx-xxx

Running heads

(verso) G.A.Bingham et al

(recto) Rapid manufactured textiles

\section{Rapid Manufactured Textiles}

G.A.Bingham $^{1 *}$, R.J.M.Hague ${ }^{1}$, C.J.Tuck ${ }^{1}$, A.C.Long ${ }^{2}$, J.J.Crookston ${ }^{2}$, M.N.Sherburn ${ }^{2}$

1The Rapid Manufacturing Research Group, Wolfson School of Mechanical and Manufacturing Engineering, Loughborough University, Leicestershire, LE11 3TU

2The Polymer Composites Research Group, School of Mechanical, Materials and Manufacturing Engineering, University of Nottingham, University Park Nottingham, NG7 2RD

*Corresponding author. Email: G.A.Bingham@lboro.ac.uk

Abstract: Rapid Manufacturing (RM) is increasingly becoming a viable manufacturing process due to dramatic advantages that are achievable in the area of design complexity. Through the exploration of the design freedom afforded by RM, this paper introduces the concept and novel research area of RM textiles. The paper highlights the design and manufacturing possibilities applied to textiles when considering additive manufacturing techniques, the current limitations of conventional Computer Aided Design (CAD) software when creating RM textile three dimensional (3D) data and the potential use of dedicated 'textile CAD'. A methodology for the generation of 3D conformal RM textile articles is presented in addition to the initial investigation of 'efficient manufacture' by the collapsing of RM textile structures into their lowest potential energy state. The work concludes that through the utilisation of RM it is entirely possible to manufacture a structure that incorporates drape and free movement properties directly comparable to conventional textiles.

Keywords: Rapid Manufacturing, Textiles, Smart textile, Design complexity

\section{AMS Subject Classification:}

\section{INTRODUCTION}

This paper describes the potential new application of manufacturing textiles through future Rapid Manufacturing (RM) technologies. As this is an entirely new application for RM, the authors intend that this paper be viewed as a precursor to further research that is needed to fully explore the potential of Rapid Manufactured textiles. All of the findings discussed are the subject of current research being undertaken by the authors (Hague 2003, Hague 2005 \& Long 2005).

RM has become a generic term used for a classification of technologies enabling the manufacture of end-use components without the application of conventional tooling (Hopkinson et al 2005). Utilising additive layered manufacturing techniques similar to those developed in Rapid Prototyping (RP), components are manufactured directly from a three-dimensional (3D) Computer Aided Design (CAD) model (Wohlers 2005). Conventional manufacturing processes are generally subtractive or formative in nature, where the manufacturing element of the production process refers to the removal or moulding of material when creating 
a desired geometry. In contrast, RM technologies utilise additive manufacturing techniques. Here, discreet slices are taken from the 3D CAD geometry. The slices taken relate directly to the build layers of the RM process targeted for manufacture. The continual recreation of the discreet adjacent slices, layer by layer, via the RM system, allows the manufacture of virtually any complexity of geometry (Hague et al 2003b). The methods in which these layers are produced and the materials in which the components are built, vary significantly between the differing systems within the classification of the technology (Chua et al 2003).

\subsection{Design freedom of RM}

One of the main drivers for the creation of current and future RM systems and their respective build materials comes from the dramatic advantages that are possible in the area of product and component design (Campbell et al 2003 \& Hague et al 2004). These advantages present a principal reason why some organisations are willing and able to accommodate the limitations associated with current additive manufacturing systems to gain a competitive design edge today (Hague 2005b).

The main benefit to be gained by utilising an additive manufacturing approach comes from the ability to produce parts of virtually any complexity, entirely without the need for tooling (Campbell et al 2003 \& Hague et al 2003b). Considering conventional manufacturing, a direct link exists between the complexity of a part and its subsequent manufacturing cost. In addition, the need for tooling in conventional manufacturing represents one of the most restrictive factors for today's product design. The absence of this tooling requirement when utilising additive manufacturing means that many of the restrictions of 'Design for Manufacture \& Assembly' (DFMA) (Boothroyd et al 1994) that are essential in a modern manufacturing environment can be eradicated (Mansour \& Hague 2003). Within injection moulding for example, the need to consider the extraction of the part from the tool takes an overriding influence on the design of the component. Therefore the high cost and need for tooling greatly restricts product design and compromises must be made. Without the need for tooling or the necessity to consider any form of DFMA, the possibilities for design become limited only by the imagination.

This revolutionary aspect of RM means that geometry will no longer be a limiting factor and negates the requirement for high volumes to offset the burden of tooling costs. Through RM, the possibility for affordable highly complex, custom parts becomes apparent. In theory, each part that is produced could be customised and therefore the potential becomes the economical 'manufacture to a unit of one' (DTI 2000 \& Hague et al 2004). The capability of RM to manufacture any complexity of design means that one is entering a new dimension of 'Manufacture for Design' rather the than the more conventional 'Design for Manufacture' philosophy (Campbell et al 2003). The elimination of tooling and the subsequent removal of many DFMA criteria realised through RM systems will promote significant benefits in the area of design. Cited benefits to product design include (Hopkinson et al 2005):

- Design complexity / Optimisation

- Parts consolidation

- Body-fitting customisation

- Multiple assemblies manufactured as one

- Multiple free moving assemblies manufactured as one

While the subject of "Design for Rapid Manufacture" (Hague et al 2004) and its impact on product design is potentially broad, this paper focuses on the micro level or meso level design opportunities that are realised 
through RM and specifically, the potential to manufacture micro/meso level free moving assemblies in one manufacturing process, i.e. Rapid Manufactured textiles.

\subsection{Scope of RM textiles}

This entirely novel area has received virtually no consideration for RM, but is one that has vast and exciting potential for future applications. While current RM textiles will not replace conventional fibre based textile production for the manufacture of simple or affordable clothing, several current niche textile markets do exist that can fully exploit the potential of RM textiles. Such markets include the high performance textile market and the smart or intelligent textile market.

Increasingly, smart and high performance textiles are seen as relevant research areas (Smart-textiles 2005a \& Smart-textiles 2005b), as new technology in contemporary textiles serves to narrow the gap between the differing sectors of art, design, engineering and science. The term 'smart textile' was first derived from a concept defined in Japan around 1990, concerning intelligent or smart materials (Takagi 1990 \& Langenhoven $\&$ Hertleer 2004). Smart textiles are defined by their ability to sense stimuli from the environment and have the inherent capability to react and adapt to them by the integration of functionalities within the textile structure (Zhang \& Tao 2001a, Zhang \& Tao 2001b \& Zhang \& Tao 2001c). Almost all current research within the area of smart textiles pursues the integration of electronic devices into conventional fibre based textiles. For example, it may soon be possible to integrate the mobile phone, PDA and MP3 player all into one smart item of clothing (Braddock \& O’Mahony 1998 \& Langenhoven \& Hertleer 2004). An important distinction here is that high performance textiles are not smart textiles. For high performance textiles, the emphasis remains the mechanical functionality, such as high strength (i.e. Kevlar ${ }^{\mathrm{TM}}$ ) or breathability (i.e. Gore-Tex $\left.{ }^{\mathrm{TM}}\right)$, therefore high performance textiles are not deemed to be intelligent.

Although smart and high performance textiles have a myriad of applications, most current research and development has centred on smart and high performance clothing (MIT 1992, Jayaraman 1996, Braddock \& O’Mahony 1998 \& Langenhoven \& Hertleer 2004) with the possible list of applications being significant. However, for smart and high performance garments to become a manufacturing reality, especially custom fitting items, several basic issues need addressing. The distinct unresolved issue that surrounds both smart and high performance textiles is their geometrical complexity and the subsequent need for a suitable manufacturing technique. Given the design complexity advantages that are afforded by RM, this issue is broadly solved if an additive approach is taken and thus the potential for RM textiles is considerable, albeit with significant research required.

\subsection{RM textiles fundamentals}

The cited benefits of RM in the area of product design, includes the ability to produce micro level or meso level free moving assemblies in one manufacturing process. Therefore, RM has the inherent capability to manufacture a type of structure or assembly that possesses drape and free movement; properties that are directly comparable to that of conventional fibre based textiles. When considering the structure of Maille (or chain-mail), utilised for armour before the $14^{\text {th }}$ century (Blair 1972), as demonstrated in Figure 1, then it becomes apparent that RM has the capability to additively manufacture an entire sheet of chain mail in one manufacturing process. This was first proposed by Evenhuis \& Kyttanen in 1999 (Kyttanen \& Evenhuis 2003 \& Freedom of Creation 2005).

[Insert figure 1 about here] 
Figure 1: Historical examples of Maille or Chain-mail link configurations

The present requirement for RM textiles is to move away from continuous fibre type geometry, as demonstrated in Figure 2, to individual links or linkable geometry, as demonstrated in Figure 3. The utilisation of such linkable geometry therefore provides the required free movement and drape characteristics inherent in conventional manufactured textiles.

\section{[Insert figure 2 about here]}

Figure 2: Conventional fibre based textiles, (left) knitted textile, (right) woven textile

[Insert figure 3 about here]

Figure 3: RM chain-mail textile

The structure of conventional manufactured textiles can be considered to be hierarchical, with the fibre (either staple: very short; or filament: longer) representing the smallest component within the hierarchy. Fibres are used to manufacture yarns or threads through processes such as spinning, and sequentially, threads are then used to manufacture textiles. The eventual textile manufacturing process relies on centuries old principles such as 'weaving' and, more recently, 'knitting'. As with any other product, textiles have to be constructed with the manufacturing process in mind and therefore are fundamentally limited by the need to consider DFMA criteria. If this point were extrapolated further, then conformal textiles articles such as "cut and sewn" garments constructed from flat sections of textile suffer from DFMA criteria twice, once during the manufacture of the textile itself, and secondly, through the manufacture of the garment from several flat textile sheets.

The potential of RM textiles is that DFMA criteria can be almost completely eradicated from the entire process. Firstly, the actual link or linkable geometry of the RM textile, due to the immense design freedom and manufacturing possibilities afforded by RM, could be any complexity of geometry. While the linkable geometry must have the inherent capability of interlinking with the adjacent structures and provide degrees of freedom for movement and drape characteristics, this is the only requirement placed upon it. Therefore the linkable geometry could be almost any smart or simple structure designed for a particular functionality. While only simple links have been considered so far, the potential exists to incorporate fully optimised smart structures, flexible linkages promoting elastic properties, hollow structures for thermal insulation, enclosed pockets for buoyancy and many other possible structures only limited by the imagination. Secondly, if one considers the manufacture of a RM garment, there would be no requirement to manufacture flat sheets of RM textile and then subsequently utilise those to produce a conformal garment. Within the design and CAD phase of the RM process, it would be possible to create a conformal seamless garment that required no DFMA criteria. Utilising this methodology it would be possible to create an entire garment in one manufacturing process, negating a large proportion of stages currently required within the conventional textile manufacturing sector. 


\subsection{INITIAL WORK UNDERTAKEN}

\subsection{Conventional CAD}

The main requirement of RM is to have a robust 3D CAD model of the target geometry to be manufactured. When manufacturing standardised macro level components via additive manufacturing, CAD representation is not a problematic issue. This is due to the shape and size of the target geometry and the design of the CAD systems, which have been developed to support mainstream manufacturing techniques. When dealing with additive manufacturing techniques it is possible to manufacture any geometry that can be created within a CAD system. However, CAD has not been developed with the capabilities of additive manufacturing in mind and therefore it is possible to manufacture several geometries via additive manufacture that can not be represented in conventional CAD. Klein bottles and Steiner surfaces are such examples.

When creating 3D RM textile CAD data, it becomes necessary to model each individual link in the entire interlinking assembly. However, while the generation of simple link configurations and the subsequent generation of flat sheets of RM textiles (demonstrated in Figure 3) within conventional CAD is not a difficult operation for experienced CAD users, problems do arise when considering $3 \mathrm{D}$ conformal geometries. If a more complex geometry is considered, where the curvature of the final net shape of the RM textile article represents curvature in all three Cartesian axes, such as the hemisphere demonstrated in Figure 4, then current CAD systems are simply not capable of successfully or automatically mapping links over the surface in a uniform fashion so that the links tessellate correctly, (also demonstrated in Figure 4).

[Insert figure 4 about here]

Figure 4: Hemispherical RM textile article, highlighting the inadequacies of conventional CAD

With sufficient time and the acceptance of extensive rework, it is possible to generate a complex 3D conformal RM textile in conventional CAD. This is demonstrated in Figure 5, which shows a CAD model and the subsequently produced world's first 3D conformal seamless RM textile garment (Bingham 2004). However, the CAD model for this article required two months to construct. The RM textile garment was manufactured using a Laser Sintering (LS) RP system.

[Insert figure 5 about here]

Figure 5: World's first 3D conformal RM textile garment, designed by Guy Bingham, CAD model (Left), actual Model (centre \& Right)

Therefore, it can be concluded that conventional CAD systems, that have not been designed with the application of RM textiles in mind, do not have the inherent capabilities required for the generation of complex curved RM textile structures, hence there is a requirement to use an alternative to 3D CAD for the generation of 3D conformal data. As modelling complex 3D textile structures is difficult and time consuming (Brown 2003), the ability to create curved textile structures represents a vital step in the generation of conformal RM smart and high performance textiles. 


\subsection{Textile CAD}

Dedicated textile 'CAD' packages do exist and have been investigated for their potential use for RM textiles (Robitaille et al 1999, Plath 2000, Lomov 2001 \& Assyst 2005). A common feature of textile CAD packages is the concept of the Representative Volume Element (RVE). The RVE is the smallest possible repeating volumetric element and often the only part of the textile to be geometrically modelled. For reference, a representation of a basic chain-mail link and its associated RVE is shown in Figure 6.

\section{[Insert figure 6 about here]}

Figure 6: Basic RM textile chain-mail link and the associated RVE

Once the concept of utilising an RVE had been recognised, a methodology of mapping this over a conformal 3D surface was required. This approach was further investigated and a methodology established for the generation of complex 3D conformal RM textile structures, as follows:

- 3D Surface incorporating the final net shape of the desired RM textile created in CAD

- Finite Element Analysis (FEA) pre processor mesh formed over the 3D surface

- RVE established within the textile CAD

- RVE mapped to the enclosed sections of the FEA mesh

- Complete conformal RM textile data exported as Standard Triangulation Language (STL) format

- STL uploaded to RM system for manufacture

In order to expedite this work, collaboration was initiated with the Polymer Composites Research Group at Nottingham University to adapt some of their existing software, TexGen (Texgen 2004). The TexGen software had been developed for the accurate and comprehensive FEA modelling of the textile component of fibre reinforced composite structures (Texgen 2004). The original purpose of the software was to generate Finite Element (FE) models for mechanical analysis of dry textiles and textile composites, as well as Computational Fluid Dynamics (CFD) to model infusion of textiles during composite manufacture.

The TexGen software relies on the generation of a suitable FEA mesh. Utilising conventional stand alone FEA pre-processor software, a 3D surface of the required final net shape of the intended RM textile article can be imported and meshed. The newly created mesh can then be exported from the FEA software and imported into the TexGen system. Having already established the RVE of the particular RM textile link configuration to be utilised, the TexGen system then populates the RVE within the enclosed sections of the FEA mesh, matching the surface normal, rotation and scaling factor accordingly to relevant sections of the mesh, and thus creating the final RM textile structure.

The results of the process can be seen successfully applied to the example of the hemisphere, as detailed in Figure 7.

\section{[Insert figure 7 about here]}

Figure 7: FEA mesh and TexGen created RM textile hemisphere

The modified TexGen system produced this particular RM textile hemisphere within a 2 minute time frame. While the RM textile article produced using this system is not fully uniform, the system required no 
intervention and was fully automated once the FEA mesh had been imported and the RVE fully established. Further examples of complex 3D conformal RM textile articles that have been produced using this methodology are shown in Figure 8 . These 3D geometries are readily manufactured via additive manufacturing as they are generated in the required STL format. The adaptation of the TexGen system thus offers a complete process for the generation of curved RM textile STL files and provides an important step forward.

\section{[Insert figure 8 about here]}

Figure 8: Further examples of complex RM textile articles created from TexGen

The use of the adapted TexGen software and highlighted methodology is exceptionally fast compared to conventional CAD. However, there are limitations. TexGen requires a vectorial description of the individual RM textile links for the RVE, from which smoothed paths are generated using simple parametric curves (e.g. Bezier curves). A 3D solid model is then generated by sweeping an assumed cross section along these paths creating the individual RM textile links. This system is therefore severely restrictive when more complex geometric shapes are considered and thus the system at present is limited to simple chain-mail type structures that can be easily defined using vectors. The ability of RM to produce highly complex geometry for the use in smart or high performance RM textiles will inevitably mean that more complex geometric link assembles will be utilised. To achieve this, a more versatile RVE geometric description methodology must be established.

Additionally, the meshes that are created within conventional FEA software are not uniform and therefore distortion and deformation of the link structure occurs when populating the RVE. This is demonstrated in Figure 9, which shows a 3D conformal surface that has been meshed using conventional FEA software and Figure 10 shows the mesh populated with a chain-mail link RVE. The resulting deformation and inconsistency of the RM textile link structures would therefore adversely affect the resultant smart or high RM textile article's performance and could additionally affect the possibility of actual manufacture. To address this issue, a uniform grid meshing algorithm must be established for the creation of more suitable FEA meshes.

[Insert figure 9 about here]

Figure 9: Non-uniform FEA meshing of conformal surfaces

[Insert figure 10 about here]

Figure 10: RVE populated FEA mesh, highlighting deformation of link structure

\subsection{Efficient Manufacture of RM textile articles}

Another issue investigated concerns the subsequent manufacture of 3D conformal RM textile articles and the need to minimise the build height of the part. When utilising additive manufacturing techniques, it is always preferable to limit the " $Z$ " height or number of layers required for manufacture of the geometry in question. This not only decreases the required build time of the geometry but minimises the cost and raw material usage (Wohlers 2005). 
When considering the manufacture of RM textile articles, sheets, garments or products, the design and CAD data must directly mimic the final intended net shape. If a simple RM textile garment is considered, such as a T-shirt as demonstrated in Figure 11, then the actual volume of the manufactured elements of the geometry (the individual links), is far less then the entire volume occupied by the larger garment assembly. The additive manufacture of the simple $\mathrm{RM}$ textile $\mathrm{T}$ shirt in its final intended shape therefore presents major inefficiencies.

[Insert figure 11 about here]

Figure 11: RM textile T-shirt

[Insert figure 12 about here]

Figure 12: RM textile cylinder

To address this inefficiency the intended final properties of the RM textile must be considered. In order for the RM textile to be deemed a textile, it must incorporate free movement and drape characteristics. Therefore, if a simple RM textile cylinder is considered, as demonstrated in Figure 12, when manufactured and unsupported, the entire structure would collapse under gravity to its lowest potential energy state, demonstrated in [Insert figure 13 about here]

Figure 13. However, when supported, after manufacture, the RM textile cylinder would regain the intended net shape as designed within the CAD phase, a simple cylinder.

[Insert figure 13 about here]

Figure 13: Collapsed (lowest potential energy state) RM textile cylinder

Therefore, using this principle, it becomes possible to design any RM textile article in its intended final net shape, collapse the entire structure under gravity within the CAD phase and export the newly collapsed structure for manufacture.

The important issue when initiating the controlled collapse of RM textiles structures is that of link separation. The link separation is required for successful manufacture and must be maintained throughout the collapsing phase. Failure to maintain this separation between interlinking geometry will result in the manufacture of a mass of fused links, negating any desired free movement and drape characteristics, which represents the main difficulty in this type of operation.

The initial work undertaken has established a methodology for performing the controlled collapse for simple link configurations utilising computer simulated gravity and link separation boundaries, as demonstrated in Figure 14. However, further work is required to extend this to more complex link configurations and RM textile articles that involve greater numbers of links and individual links of increasing geometric complexity.

[Insert figure 14 about here]

Figure 14: RM textile cylinder controlled collapse 


\subsection{CONCLUSION}

With the manufacture of textiles by Rapid Manufacturing techniques, incorporating its immense design freedom and unrivalled ability to manufacture geometry of increasing complexity without the need of tooling, the concept of designing textiles entirely for specific applications with no DFMA criteria becomes a manufacturing reality. The ability to manufacture textiles that are tailored to specific applications would enable the generation of new and hybrid textiles for a multitude of current applications and new applications only realised through the manufacture of functional specific RM textiles. In addition, the application of Rapid Manufacturing can enable the manufacture of fully finished customised items of clothing, new high-tech smart textiles capable of executing specifically designated tasks, components that transition from solid to textile, such as optimised footwear, and the potential to give textiles added functionality through design. If the paradigm of Rapid Manufactured functional graded materials develops as predicted, the generation of smart clothing with integrated circuitry, sensors and actuators becomes entirely possible in one manufacturing process.

In summary, the initial work that has been undertaken so far has significantly advanced the subject area of RM textiles for the generation of smart and high performance textiles. However, in order for the subject to progress, advances need to be made in the uniform mapping of links (using uniform grid meshing algorithms), the use of more complex link structures (other than chain-mail), processing of the large datasets and the collapsing of the textile macro-structure into the most efficient build orientation. All of these issues are the topics of the current research being undertaken by the authors.

\section{REFERENCES}

Assyst Bullmer., 2005, Commercial textile modelling software, website, www.assyst-us.com/ (accessed march 2004)

Bingham, G.A., 2004, 'World's first conformal RM textile garment' Created at Loughborough University, Designed by Guy Bingham. Available online,

www.3dsystems.com/newsevents/events/slsusersgroups/2004/exc_awards_details_sls.asp

Blair, C., 1972, European Armour rev. edition. London, B.T. Batsford, Ltd. First edition 1958, revised edition 1972.

Boothroyd, G., Dewhurst, P., Knight, W., 1994, Product design for manufacture and assembly, Marcel Dekker Inc., New York.

Braddock, S.E., O'Mahony, M., 1998, Techno Textiles $2^{\text {nd }}$ edition, Thames and Hudson LTD 181A Holborn London WC1V 7QX

Brown, D., 2003, 'A system for the automatic generation of solid models of woven structures'. Composites part A. 34, pp 511-515 
Campbell, R.I., Hague, R.J.M., Sener, B., \& Wormald, P.W., 2003, 'The Potential for the Bespoke Industrial Designer', The Design Journal. 6, pp 24-34

Chua, C.K., Leong, K.F., \& Lim, C.S., 2003, 'Rapid Prototyping: Principles and Applications', 2nd edition. World scientific publishing Co. Pte. Ltd. 5 Toh Tuck Link, Singapore 596224. UK office: Suite 202, 1060 Main Street, River Edge, NJ 07661.

DTI,. 2000, UK Manufacturing: 'We can make it better'. Foresight Manufacturing 2020 Panel, Final Report, Findlay Publications, p12. Available online, www.foresight.gov.uk/Previous_Rounds/Foresight_1999_2002/Manufacturing_2020/Reports/We\%20can $\% 20$ make\%20it\%20better/M2020.pdf

Freedom of Creation., 2003 company website, www.freedomofcreation.com (accessed December 2003)

Hague, R.J.M., 2003, EPSRC, IMRC 69: Design and Optimisation of Complex Rapid Manufactured Smart Textures \& Textiles

Hague, R.J.M., Campbell, R.I. \& Dickens, P.M., 2003b "Implications on Design of Rapid Manufacturing" , Proceedings of the Institution of Mechanical Engineers, Part C: Journal of Mechanical Engineering Science. 217, January 2003, pp 25-30

Hague, R.J.M., Mansour, S. \& Saleh, N., 2004, 'Material and design considerations for Rapid Manufacturing', IJPR. 42, November 2004, pp 4691-4708

Hague, R.J.M., 2005, EPSRC, IMRC 158: The generation of conformal 3D data for Rapid Manufactured Smart \& High performance textiles

Hague, R.J.M., 2005b, Chapter 2: Unlocking the design potential of Rapid Manufacturing. Eds: Hopkinson, N., Hague, R.J.M., \& Dickens, P.M., 2005, 'Rapid Manufacturing - An Industrial Revolution for the Digital Age', John Wiley \& Sons, Ltd.

Hopkinson, N., Hague, R.J.M., \& Dickens, P.M., 2005, 'Rapid Manufacturing - An Industrial Revolution for the Digital Age', John Wiley \& Sons, Ltd.

Jayaraman, S., 1996, Georgia Tech smart shirt project, available online, www.tfe.gatech.edu/ (accessed May 2005)

Kyttanen, J., \& Evenhuis, J., 2003, 'Method and device for manufacturing fabric material', European patent No. WO03082550, 2003-10-09

Langenhove, L. V., \& Hertleer, C., 2004 'Smart clothing: a new life' International Journal of Clothing Science and Technology. 16, 2004, pp 63-72

Lomov, S. V., 2001,'Textile composites: modelling strategies’., Composites part A. 32, pp1379-1394 
Long, A.C., 2005, EPSRC, IMRC: The generation of conformal 3D data for Rapid Manufactured Smart \& High performance textiles - a feasibility study.

Mansour, S., \& Hague, R.J.M., 2003, IMechE Part B. 217, pp 453-461

MIT, Massachusetts institute of technology, media lab, 1992, 'Musical jacket project', available online, www.media.mit.edu/hyperins/levis/ (accessed December 2004)

Pizzuto, J.J., Price, A., Cohen, A. C., \& Johnson, I., 1999, 'Fabric science $7^{\text {th }}$ ed'. New York : Fairchild

Plath, J., 2000, 'Realistic modelling of textiles using interacting particle systems'. Computer and graphics. 24, pp879-905

Robitaille, F., Clayton, B.R., Long, A.C., Souter, B.J., \& Rudd, C.D., 1999, 'Geometric modeling of industrial preforms: Woven and braided textiles'. Journal of Materials: Design and Applications, Proc. Institution of Mechanical Engineers (Part L), 213. pp 69-84

Smart-textiles, 2005a, EPSRC smart-textiles information website, www.smartextiles.co.uk/, (accessed January 2005)

Smart-textiles, 2005b, Research Institute for Flexible Materials, Heriot-Watt University, Scottish Borders Campus, Netherdale, Galashiels TD1 3HF, United Kingdom. www.smartextiles.info/ (accessed January 2005)

Takagi, T., 1990, ‘A concept of intelligent materials', J. of Materials System Structures. 1, pp149-156

TexGen, 2004, TexGen software website, www.nottingham.ac.uk/\%7Eemxmns/texgen.htm (accessed April 2004)

Wohlers, T., 2005, Wohlers report, Rapid Prototyping, Tooling \& Manufacturing State of the Industry, Annual worldwide Progress report Wohlers associates, Inc. Oakridge retail park, 1511 River Oak Road, Fort Collins, Colorado 80525 USA

Zhang, X., \& Tao, X., 2001a, 'Smart textiles: passive smart', Textile Asia, June 2001. pp 45-49

Zhang, X., \& Tao, X., 2001b, 'Smart textiles: active smart', Textile Asia, July 2001. pp 49-52

Zhang, X., \& Tao, X., 2001c, 'Smart textiles: very smart', Textile Asia, August 2001. pp 35-37 


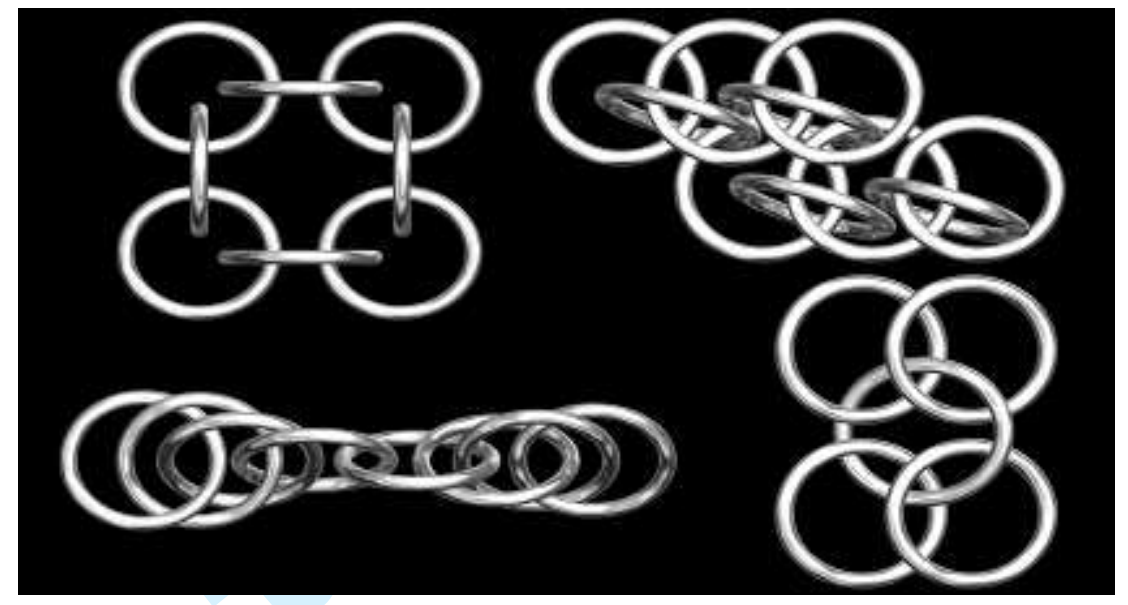




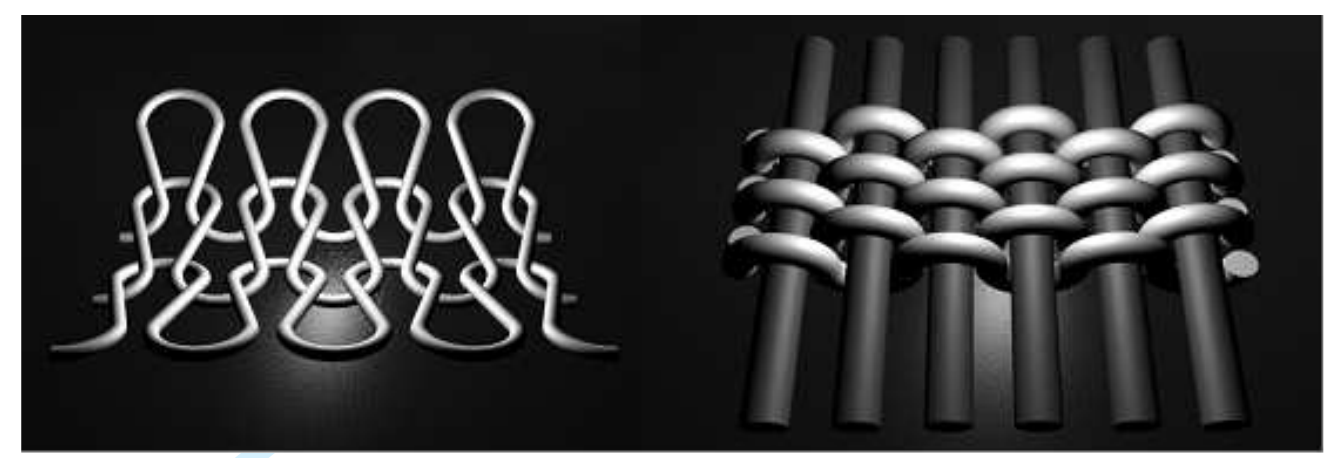




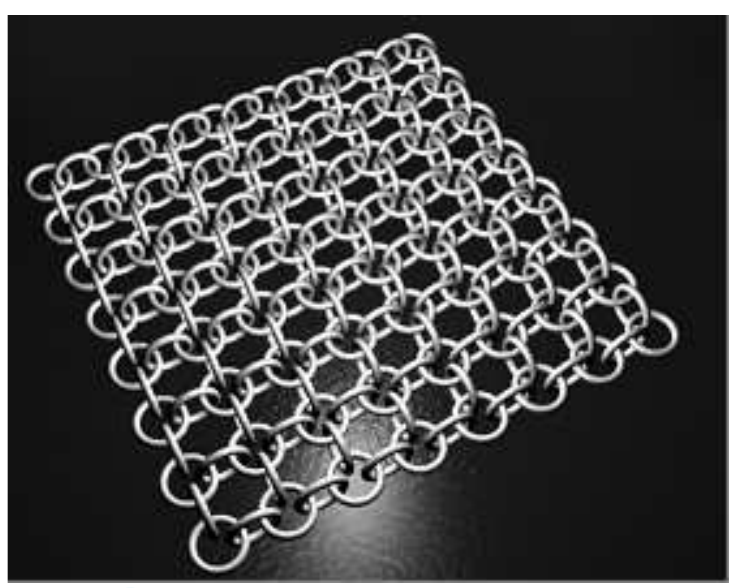

URL: http://mc.manuscriptcentral.com/tandf/tcim Email:ijcim@bath.ac.uk 


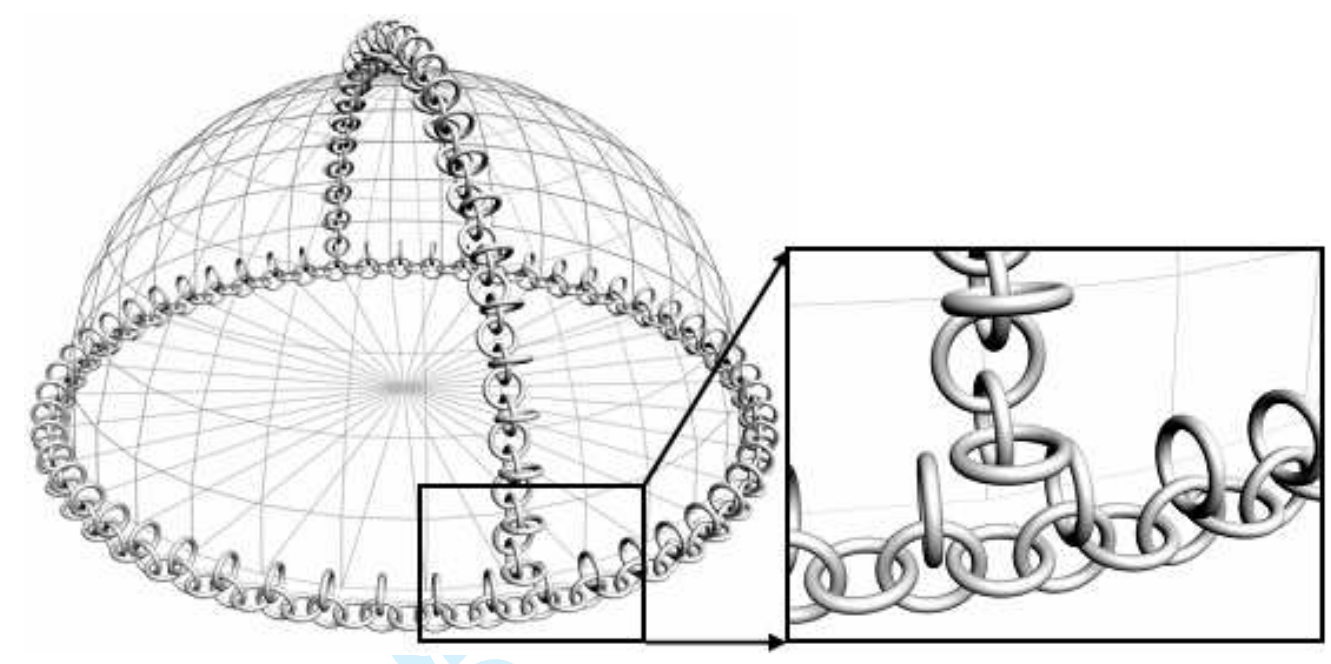

URL: http://mc.manuscriptcentral.com/tandf/tcim Email:ijcim@bath.ac.uk 

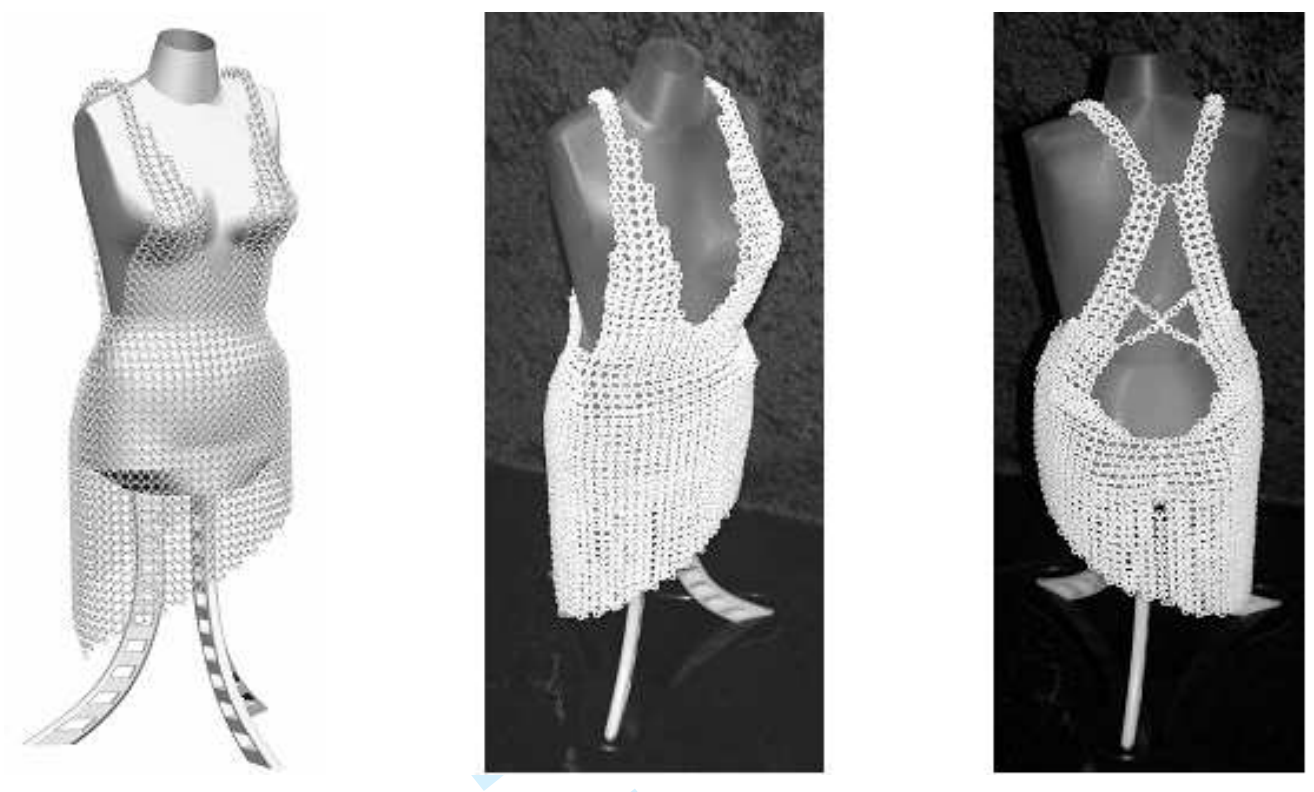


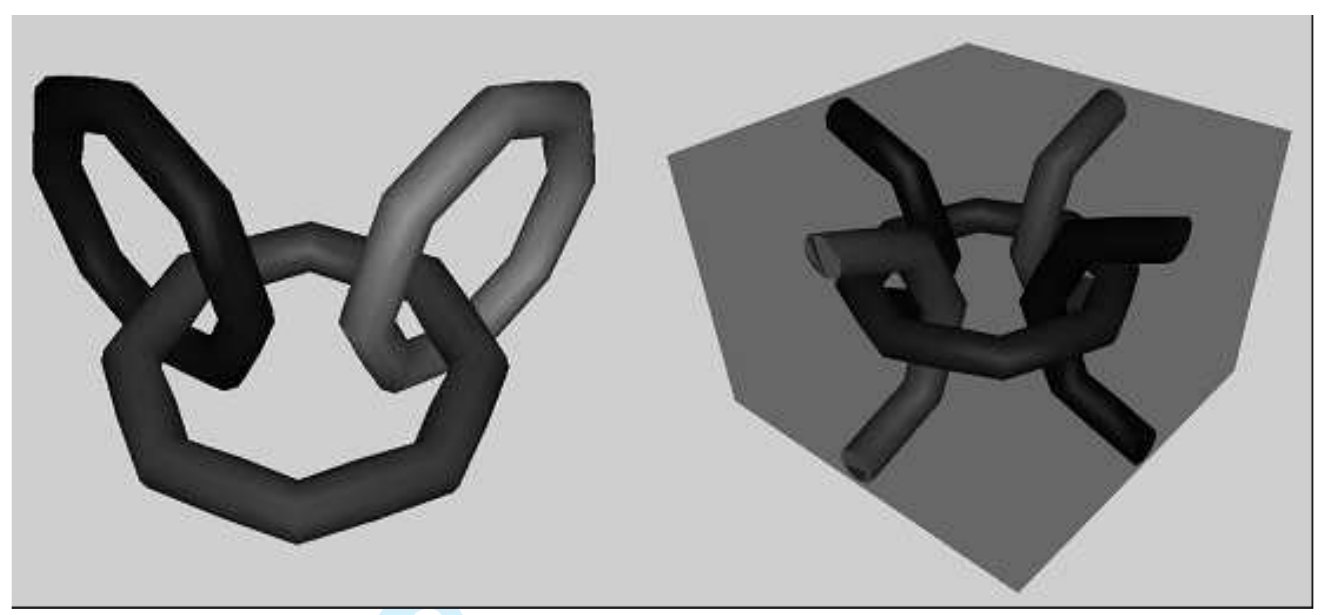

URL: http://mc.manuscriptcentral.com/tandf/tcim Email:ijcim@bath.ac.uk 


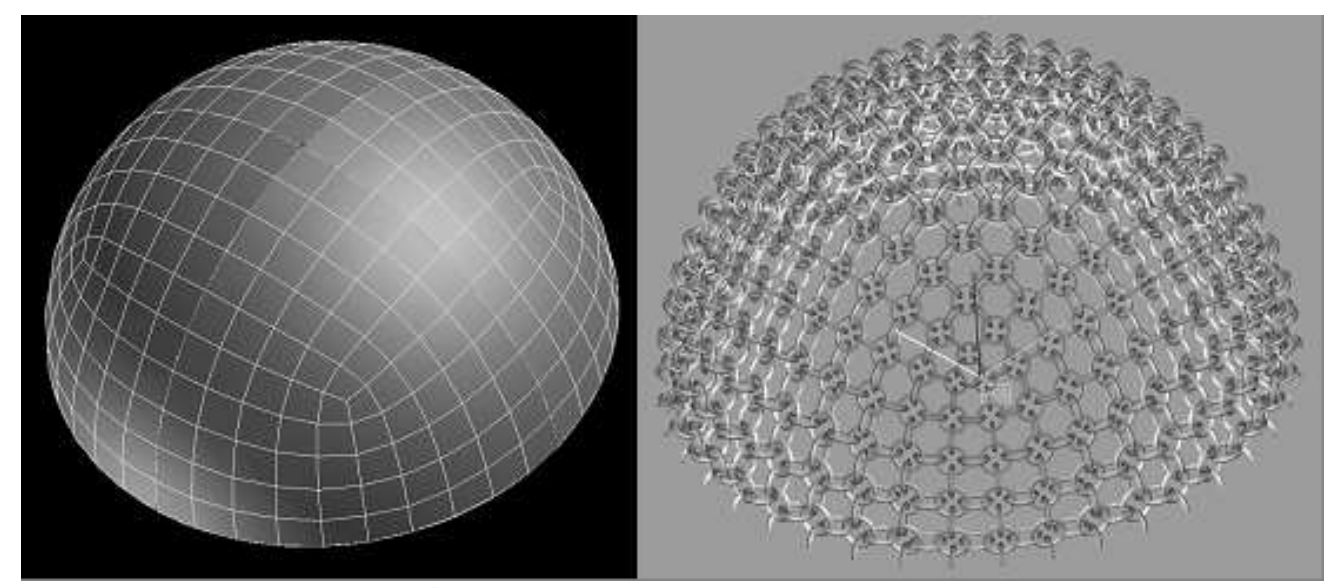

URL: http://mc.manuscriptcentral.com/tandf/tcim Email:ijcim@bath.ac.uk 


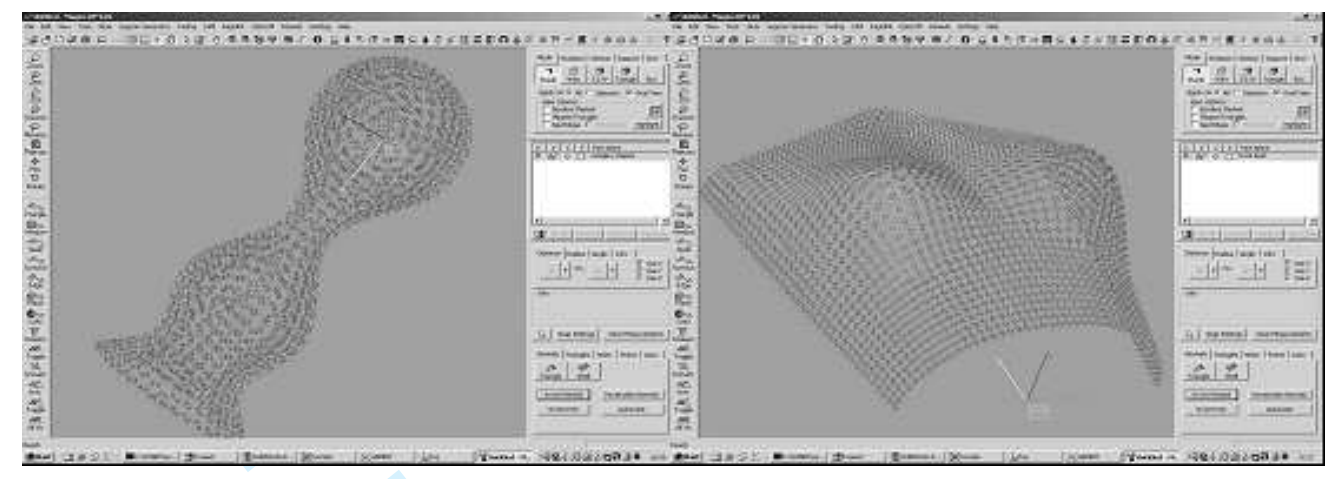

URL: http://mc.manuscriptcentral.com/tandf/tcim Email:ijcim@bath.ac.uk 


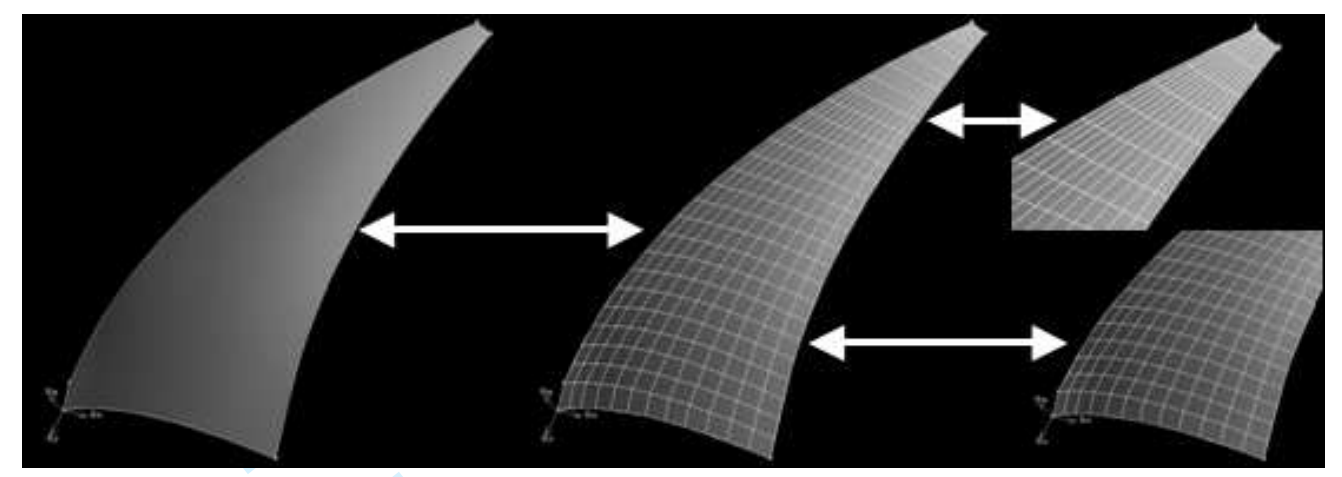




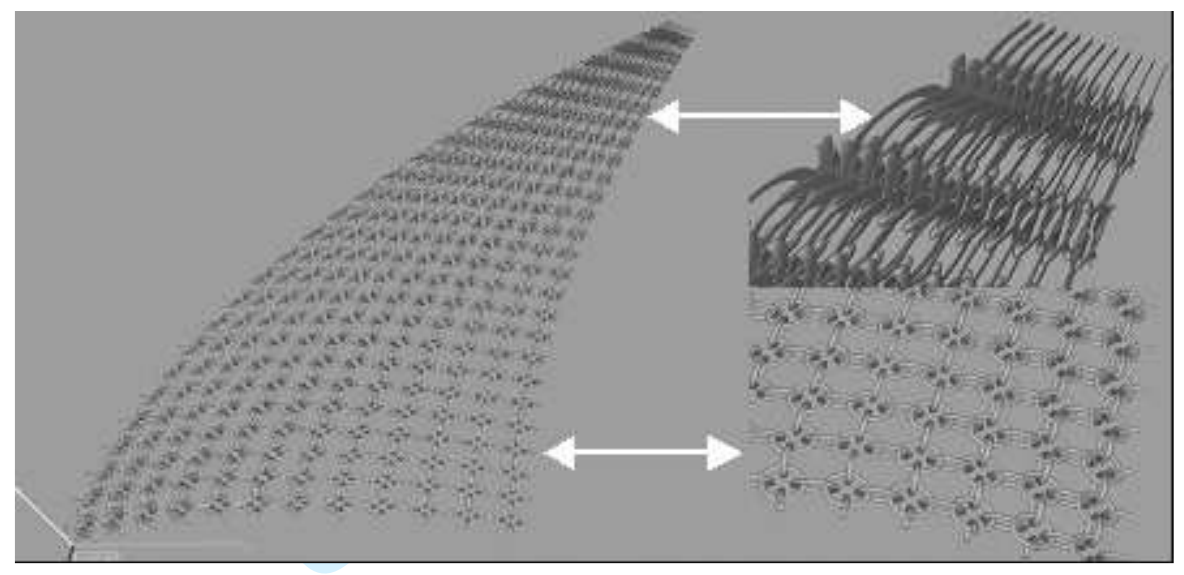

URL: http://mc.manuscriptcentral.com/tandf/tcim Email:ijcim@bath.ac.uk 


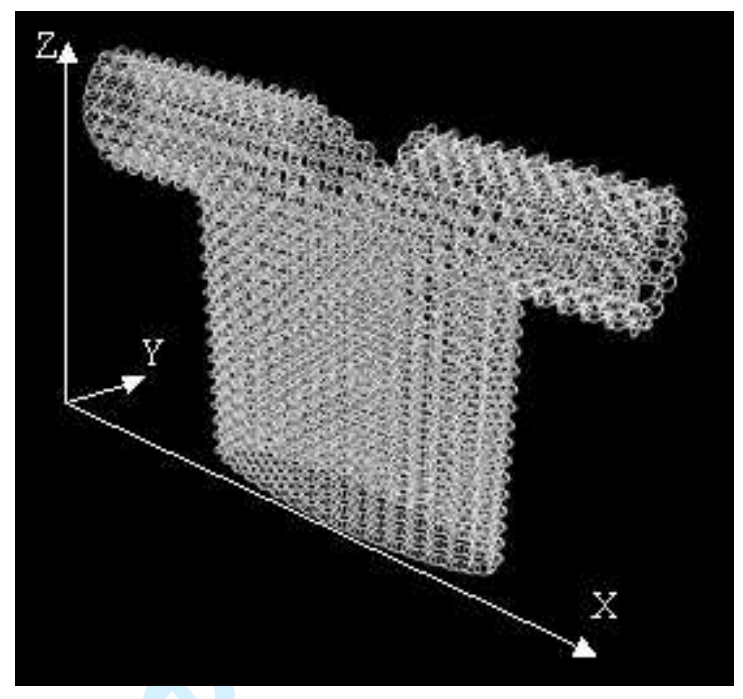

URL: http://mc.manuscriptcentral.com/tandf/tcim Email:ijcim@bath.ac.uk 


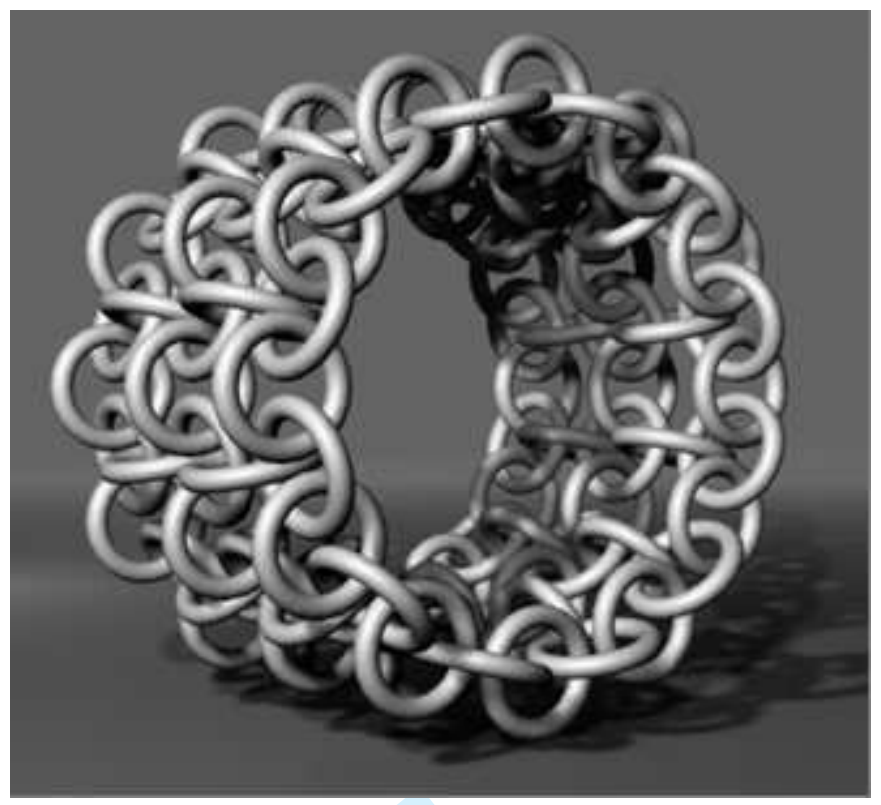




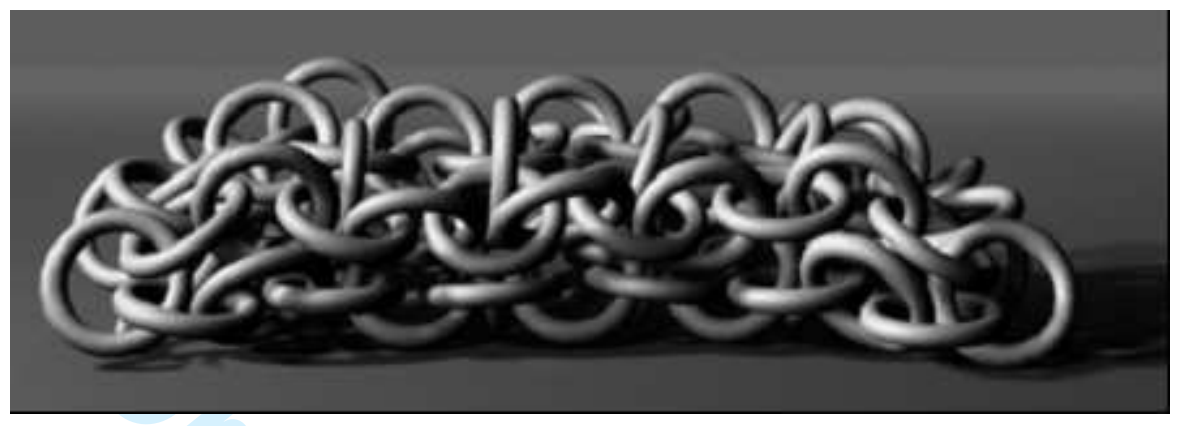

URL: http://mc.manuscriptcentral.com/tandf/tcim Email:ijcim@bath.ac.uk 


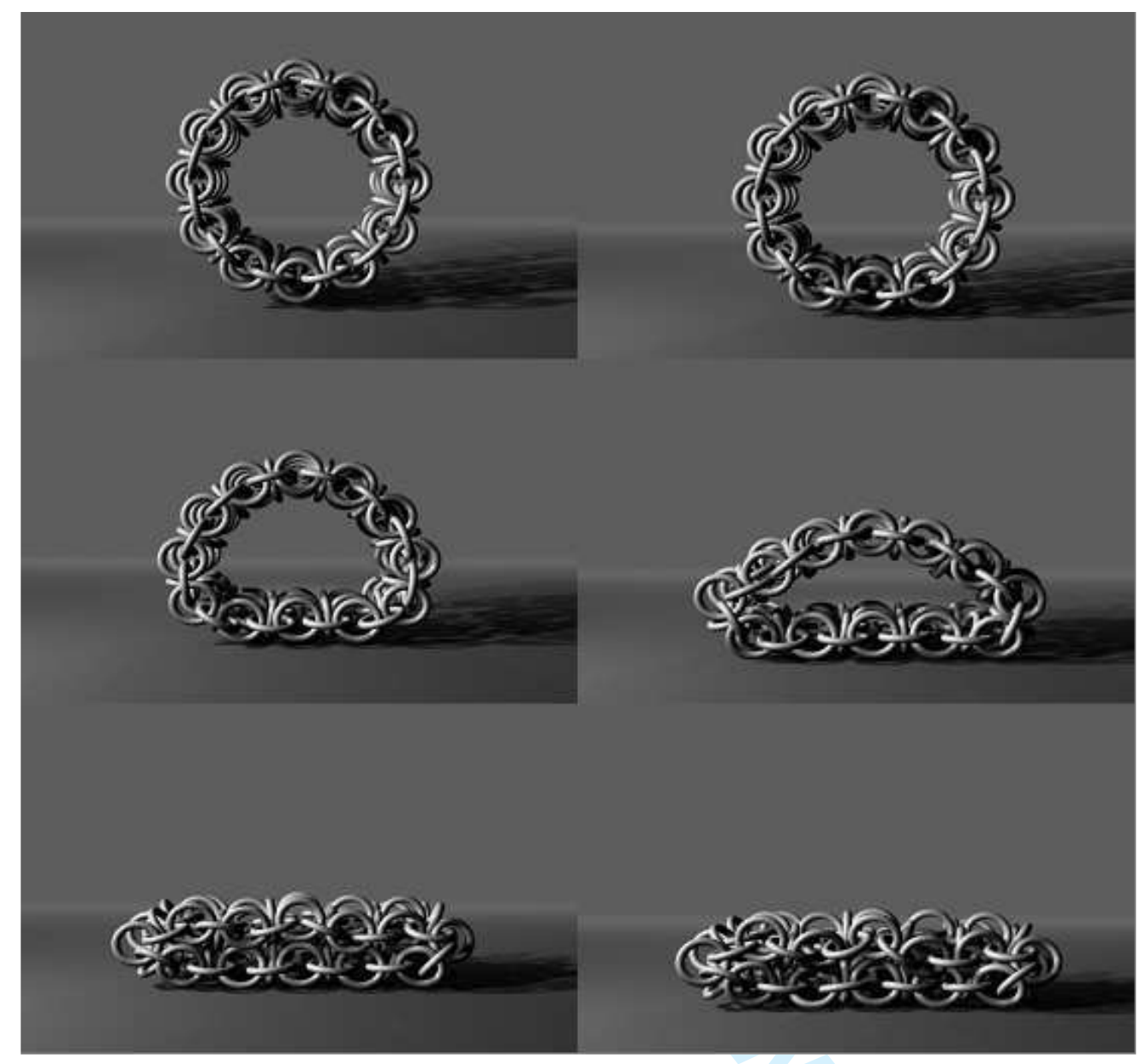


TCIM-2006-IJCIM-0030.R1

Figure 1: $\quad$ Historical examples of Maille or Chain-mail link configurations

Figure 2: Conventional fibre based textiles, (left) knitted textile, (right) woven textile

Figure 3: $\quad$ RM chain-mail textile

Figure 4: Hemispherical RM textile article, highlighting the inadequacies of conventional CAD

Figure 5: World's first 3D conformal RM textile garment, designed by Guy Bingham, CAD model (Left), actual Model (centre \& Right)

Figure 6: Basic RM textile chain-mail link and the associated RVE

Figure 7: $\quad$ FEA mesh and TexGen created RM textile hemisphere

Figure 8: $\quad$ Further examples of complex RM textile articles created from TexGen

Figure 9: $\quad$ Non-uniform FEA meshing of conformal surfaces

Figure 10: RVE populated FEA mesh, highlighting deformation of link structure

Figure 11: $\quad$ RM textile T-shirt

Figure 12: RM textile cylinder

Figure 13: Collapsed (lowest potential energy state) RM textilecylinder

Figure 14: $\quad$ RM textile cylinder controlled collapse 